\title{
The treatment of adult scoliosis utilizing the SpineCor Dynamic Corrective Brace
}

\author{
L Marcotte*, C Coillard, P Dion and CH Rivard
}

Address: Posturetek 2823 Boulevard Rosemont Montréal, Québec, H1Y 1L6, Canada

Email: L Marcotte* - dremarcotte@posturetek.com

* Corresponding author

from 6th International Conference on Conservative Management of Spinal Deformities

Lyon, France. 21-23 May 2009

Published: 14 December 2009

Scoliosis 2009, 4(Suppl 2):O52 doi:I0.1 I86/I748-7|6I-4-S2-O52

This abstract is available from: http://www.scoliosisjournal.com/content/4/S2/O52

(C) 2009 Marcotte et al; licensee BioMed Central Ltd.

\section{Introduction}

Scoliosis and spinal deformities offer little hope for rehabilitation in the adult population. Pain and viscerosomatic dysfunction are frequently encountered, and conventional medical care uses rigid bracing, medication and surgery in the most serious cases. The treatment of adult scoliosis with The SpineCor Dynamic Corrective Brace deserves more attention. It offers a great variety of combinations to improve spinal alignment and posture, and depending on the curve type, its severity and rigidity. The main therapeutic goal is to reduce pain and the strain on the neuromusculoskeletal system. The brace acts as a dynamic support against compressive loading on the inter-vertebral joints, while creating a corrective movement in the spine which produces neuromuscular integration.

\section{Methods}

Seventy three adult scoliosis patients, 63 females and 10 males (ages between 18 and 93 years), with Cobb angles of $15^{\circ}$ to $93^{\circ}$ and curves of all types and many different etiologies, were fitted with a SpineCor ${ }^{\circledR}$ Brace.

\section{Results}

Of the 65 who have actively been wearing the SpineCor ${ }^{\oplus}$ Brace between 10 to 154 hrs/week, 29 have seen complete resolution of their symptoms while in the brace, 14 of which originally had a Numerical Pain Scale (NPS) of 5/ 10 and over. Although the brace had little effect on the curve itself, especially in older patients, and while there has been 1 reported case of aggravation in leg radiculopathy, we found an overall $60 \%$ improvement in the pain status of these patients who have been actively wearing their brace.

\section{Discussion}

These results suggest that the SpineCor ${ }^{\circledast}$ Dynamic Corrective Brace is a promising conservative method for the treatment of scoliosis in the adult population, as it improves the pain status and wellbeing of patients. 